\title{
Correction to: CS-CGMP: Clustering Scheme Using Canada Geese Migration Principle for Routing in Wireless Sensor Networks
}

\author{
A. Kavitha ${ }^{1}$ (D) Koppala Guravaiah ${ }^{2} \cdot$ R. Leela Velusamy ${ }^{1}$ \\ Published online: 4 August 2020 \\ ๑) Springer Science+Business Media, LLC, part of Springer Nature 2020
}

\section{Correction to: Wireless Personal Communications https://doi.org/10.1007/s11277-020-07632-4}

There was a mix-up of Figs. 5-8 in the initial, online publication. The original article has been corrected.

Publisher's Note Springer Nature remains neutral with regard to jurisdictional claims in published maps and institutional affiliations.

The original article can be found online at https://doi.org/10.1007/s11277-020-07632-4.

\section{A. Kavitha}

kavithada@gmail.com

Koppala Guravaiah

kguravaiah@gmail.com

R. Leela Velusamy

leela@nitt.edu

1 Department of Computer Science and Engineering, National Institute of Technology, Tiruchirapalli, Tamilnadu 620015, India

2 Department of Computer Science and Engineering, Indian Institute of Information Technology, Kottayam, Kottayam, Kerala 686635, India 